\title{
Orofaciodigital syndrome type 8
}

INSERM

\section{Source}

INSERM. (1999). Orphanet: an online rare disease and orphan drug data base.

Orofaciodigital syndrome type 8. ORPHA:2755

Oral-facial-digital syndrome, type 8 is characterized by tongue lobulation, hypoplasia of the epiglottis, median cleft upper lip, broad or bifid nasal tip, hypertelorism or telecanthus, bilateral preaxial and postaxial polydactyly, abnormal tibiae and/or radii, duplication of the halluces, short stature, and mild intellectual deficit. 